Running Head: SELF-LOCATION AS A PREDICTOR OF RELIGIOSITY

Accepted Version

The Path to God is Through the Heart:

Metaphoric Self-Location as a Predictor of Religiosity

Adam K. Fetterman ${ }^{1}$, Jacob T. Juhl ${ }^{2}$, Brian P. Meier ${ }^{3}$, Andrew Abeyta ${ }^{4}$, Clay Routledge ${ }^{4}$, \&

\author{
Michael D. Robinson ${ }^{4}$ \\ ${ }^{1}$ University of Houston \\ ${ }^{2}$ University of Southampton \\ ${ }^{3}$ Gettysburg College
}

${ }^{4}$ North Dakota State University

Note: Correspondence can be sent to Adam Fetterman, Department of Psychology, University of Houston, 3695 Cullen Boulevard, Houston, TX 77204-5022 (email: akfetterman@uh.edu). 


\begin{abstract}
Metaphors linking the heart to warm intuition and the head to cold rationality may capture important differences between people because some individuals locate the self primarily in the heart (heart-locators) and others locate the self primarily in the head (head-locators). Five studies (total $N=2575$ ) link these individual differences to religious beliefs, which are thought to follow from warm and intuitive forms of thinking. As hypothesized, Study 1 found that religious beliefs were stronger among heart-locators than head-locators. Study 2 replicated this relationship in a more diverse sample and Study 3 replicated it in another country (Germany). Studies 4 and 5 focused on questions of mediation. Heart-locators believed in God to a greater extent partly because of empathy-related processes (Study 4) and partly because they tended to think in less analytic terms (Study 5). These studies significantly extend our knowledge of how conceptual metaphors interact with personality processes.
\end{abstract}

Keywords: Self-Location, Head, Heart, Metaphor, Religiosity 


\section{The Path to God is Through the Heart: Metaphoric Self-Location as a Predictor of Religiosity}

Your heart's your best mirror. It’s where your faith lies. - Mufti Ismail Menk

Human beings have a dual existence. We are often guided by feelings, intuitions, and passions, yet we also have the capacity for rational thought (Epstein, 2003). These two ways of apprehending the world have been contrasted since the time of Plato (trans. 1987) and they have been metaphorically linked to the head versus the heart for at least this long (Lakoff \& Johnson, 1999). Indeed, Plato (trans. 1987) suggested that the head was the source of rational wisdom and the heart was the source of emotional passions, which accords with modern conceptions as well (Swan, 2009). For example, rational decisions are made by “using one’s head”, whereas emotional decisions are made by “following one’s heart” (Lakoff \& Johnson, 1999). In the present research, we show how these metaphoric associations can be levered to provide key insights into the self, with key links to personality processes as well.

\section{A Brief Introduction to Conceptual Metaphor Theory}

Prior to the 1980s, metaphors were treated as optional features of language and they tended to be viewed as poetic rather than commonplace (Gibbs, 2011). Lakoff and Johnson (1980) challenged such traditional views by highlighting, among other things, just how commonly people speak about their lives in metaphoric terms (Landau, 2018). A further insight was that metaphoric expressions seemed to follow from deeper ways of thinking rather than vice versa (Lakoff \& Johnson, 1999), which is a position now known as conceptual metaphor theory (CMT: Gibbs, 2011; Landau, 2018). 
Conceptual metaphor theory has received support in cognitive and social cognitive studies (Gibbs, 2011; Landau, Meier, \& Keefer, 2010). Consistent with metaphors linking darkness to negativity and lightness to positivity (e.g., “dark thoughts”, "bright prospects”), for example, people are faster to evaluate negative words in a black color and positive words in a white color (Meier, Robinson, \& Clore, 2004). Interactions of this type suggest that people somewhat automatically recruit the perceptual dimension of lightness-darkness when thinking about the conceptual dimension of connotative meaning (Crawford, 2009). More broadly, many studies have shown that a number of different perceptual experiences can prime metaphorically consistent social cognitions (Landau et al., 2010; Lee, 2016).

As typically presented, CMT is essentially a normative theory. That is, it holds that (all?) people think metaphorically (Lakoff \& Johnson, 1980) and will therefore be influenced in similar ways by metaphor-related inputs (Landau et al., 2010). Viewed from this perspective, the theory might have little to say about personality processes or individual differences, though this need not be the case. If metaphors channel thinking in general (Lakoff \& Johnson, 1999), then they may constrain how people think about themselves as particular people (Robinson \& Fetterman, 2014). This appears to be true for an important class of metaphors that contrast warm and intuitive thinking styles with those that are colder and more analytic.

\section{Head-Heart Metaphors as a Model of Personality}

The self is among the most important yet elusive concepts and grounding it, both conceptually and physically, can therefore be a problem (Lakoff \& Johnson, 1999). Fortunately, the self has a body and must therefore reside somewhere within it. Furthermore, nearly everyone is pretty sure that the self's location is in the body's upper half relative to its lower half (Alsmith \& Longo, 2014). Beyond this broad type of consensus, though, there is disagreement: Some 
people are pretty sure that the self is in the head; others, however, are pretty sure that it is in the heart (Limanowski \& Hecht, 2011). These individual differences can be sharpened to a point by asking participants to choose whether the brain versus the heart is more closely associated with the self: About 50\% of the population seems to choose each (Fetterman \& Robinson, 2013).

What we term self-location has a real phenomenology associated with it (Limanowski \& Hecht, 2011). For a head-locator (heart-locator), it really seems like the self exists primarily in the head (heart area: Robinson \& Fetterman, 2014). Nonetheless, this sense of self-location is both reinforced by, and reinforces, metaphoric functions ascribed to the head versus the heart (Swan, 2009; Yu, 2003). Head-locators are more likely to be men, describe themselves as logical, and are less interested in close relationship activities (e.g., talking, sharing, helping). Heart-locators, by contrast, are more likely to be women, describe themselves as emotional, and are interpersonally warmer (Fetterman \& Robinson, 2013). Fetterman and Robinson (2013) reported extensive validity evidence of this type and also showed that differences between headlocators and heart-locators cannot be equated with existing personality constructs.

Even so, what we know about "head” and "heart” people primarily relates to their personality traits. For example, head-locators describe themselves as more independent (Adam, Obodaru, \& Galinsky, 2015) and heart-locators describe themselves as more agreeable (Fetterman \& Robinson, 2013). Yet, metaphors for the head and heart encompass far more than personality traits. Indeed, at their core, these metaphors refer to processing styles or preferred ways of making decisions (Swan, 2009). To “follow one’s heart” means to make decisions intuitively, on the basis of feelings (Lakoff \& Johnson, 1999). To “use one's head”, on the other hand, means to resist immediate feelings in favor of rational, and even skeptical, considerations (Lakoff \& Johnson, 1999). In cases in which it is primarily feelings and intuition that favor a 
certain outcome, then, heart-locators should make the "leap of faith" and head-locators should resist doing so. The realm of religiosity is an excellent one for testing these ideas.

\section{Self-Locations as a Possible Predictor of Religiosity}

No previous studies have investigated whether heart-locators are more religious.

However, what we know about religious beliefs provides a basis for predicting systematic relationships. Women tend to be more religious than men (Argyle \& Beit-Hallahmi, 1975) and the percentage of heart-locators tends to be higher among women (Fetterman \& Robinson, 2013). Higher levels of femininity predict greater faithfulness (Francis \& Wilcox, 1996) and heart-locators are more feminine than head-locators (Fetterman \& Robinson, 2013). The personality trait of agreeableness is among the more robust trait-related predictors of religiosity (Saroglou, 2002) and heart-locators are more agreeable (Fetterman \& Robinson, 2013). Femininity and agreeableness are consistent with an ethic of caring, which both predicts

religiosity (Batson, Schoenrade, \& Ventis, 1993), and appears to underlie a number of the correlates of heart-location (Fetterman \& Robinson, 2013).

Also pertinent are analyses suggesting that religious beliefs may typically follow from feelings and intuition rather than analytic thinking processes (Jack, Friedman, Boyatzis, \& Taylor, 2016; Van Leeuwen, 2014). In this connection, intuitive ways of thinking favor meaning, even in the context of meaningless events (Atran \& Norenzayan, 2004; Heintzelman \& King, 2016), and they seem prone to superstitious ways of thinking (Lindeman \& Aarnio, 2007). Moreover, people who follow their feelings, particularly when they involve empathy or caring, often feel a deeper connection to their religious beliefs (Jack et al., 2016; Markstrom, Huey, Stiles, \& Krause, 2010), and individuals who lack interpersonal warmth tend to be less religious (Lowicki \& Zajenkowski, 2017). Conversely, a fairly robust body of studies have shown that 
tendencies toward analytic thinking, whether chronic (Pennycook, Ross, Koehler, \& Fugelsang, 2016) or primed (Gervais \& Norenzayan, 2012), tend to be less hospitable to religious beliefs, including beliefs in God (Morgan, 2016; Van Leeuwen, 2014).

Given these connections, it is plausible to hypothesize that heart-locators, who endorse feelings and intuition to a greater extent (Fetterman \& Robinson, 2013), should tend toward higher levels of religious belief. By contrast, head-locators, who endorse logic and seem to be interpersonally colder (Fetterman \& Robinson, 2013), should tend toward lower levels of religious belief, if not skepticism (Pennycook et al., 2016). We examined these ideas within five personality-process studies with a large combined sample size.

\section{Overview of Studies}

Self-location was assessed, as it has been assessed before, in terms of whether people locate the self primarily in the brain or the heart (Fetterman \& Robinson, 2013). We hypothesized that heart-locators would endorse religious beliefs to a greater extent than headlocators. In Study 1, hypotheses of this type were examined with respect to four questions about religious beliefs and spirituality. Study 2 concentrated on a single religious belief question, but in the context of a more diverse sample. Study 3 then sought to determine whether relations between self-location and beliefs in God are specific to English-speaking people or whether they can be found in a non-English speaking country (Germany) as well.

Study 4 had several purposes. It sought to control for personality factors and also to examine a potential mediator in the form of empathetic moral thinking. Briefly, heart-locators should be more prone to deontological (empathy-based or emotional) moral thinking, and such tendencies could partially account for their stronger beliefs in God. Study 5 then focused on another potential mediator in the form of intuitive versus analytical thinking styles. We reasoned 
that heart-locators should be more intuitive in their thinking style, which could also support their stronger beliefs in God. Altogether, the studies were designed to establish self-location as a robust predictor of religiosity while exploring plausible reasons for this relationship.

\section{Study 1}

\section{Method}

\section{Participants and Procedures}

Six hundred and two (332 female; $M$ age $=19.47$ ) undergraduate students from North Dakota State University received course credit for their participation. The measures were part of a departmental pretest survey and were completed online.

\section{Measures}

Self-location. The self is seen to have a primary location or "home base" that is either in the head or the heart (Fetterman \& Robinson, 2013). To capture individual differences of this type, we asked a simple question: "Regardless of what you know about biology, which body part do you more closely associate with your self?” The options were “brain” or "heart”. The "regardless" part of the question makes it clear that we were interested in perceptions rather than facts and the brain, rather than the head, is contrasted with the heart because both are internal bodily organs (Fetterman \& Robinson, 2013). The brain is a key source of metaphors for intellect (e.g., a "brainy" person is a smart person) whereas the heart is a key source of metaphors for intuition and feeling (e.g., “follow your heart”). For the sake of convenience, though, we refer to the measure as a head/heart measure (Fetterman \& Robinson, 2013).

Self-location is a group difference in that there are "head" people and "heart" people i.e., two separate groups that tend to be roughly equal in size (Fetterman \& Robinson, 2013). A similar result was obtained in Study 1 in that 304 participants (50.5\%) located the self in the head 
(or brain) and 298 (49.5\%) located the self in the heart. We hypothesized that the latter group would score systematically higher in religiosity than the former.

Religiosity. We sought to assess different facets of religiosity in a parsimonious manner. Fortunately, it is possible to do so by using single item measures with a high degree of face validity (Zuckerman, 2007). Such single-item measures are frequently used to track national and international trends in religiosity (Bishop, 1999) and responses to them correlate very highly with longer, often more particular, types of scales assessing various aspects of religious belief (Büssing, 2012). They are also frequently used in the psychology of religion literature (e.g., Norenzayan \& Hansen, 2006; Shenhav, Rand, \& Greene, 2012), a literature that we sought to speak to. Accordingly, we asked four questions.

First, participants were asked to characterize their level of religiosity ("In general, would you say you are a religious person?”) using a 6-point scale ( 1 = not very religious; 6 = very religious). As expected (Zuckerman, 2007), the average person was moderately religious ( $M=$ 3.79; $S D=1.59$ ). A second item ("Religious beliefs are what lie behind my whole approach to life”) sought to determine whether religious beliefs were central to the self-concept $(1=$ definitely not true of me; 6 = definitely true of me; $M=3.65 ; S D=1.62)$. In related terms, the third item (“In general, how important are religious and spiritual beliefs in your day-to-day life”) sought to determine whether religious beliefs were personally important ( 1 = not very important; 6 = very important; $M=3.66 ; S D=1.55$ ). A fourth item, finally, mirrored the first ("To what extent do you consider yourself a spiritual person?”), but with reference to spirituality rather than religion ( $1=$ not very spiritual; $7=$ very spiritual; $M=4.35 ; S D=1.73)$. The items were closely modeled on those used in national surveys (Bishop, 1999; Büssing, 2012; Zuckerman, 2007) and 
we refer to them in terms of religiosity (first item), self-centrality (second item), importance (third item), and spirituality (fourth item).

\section{Results}

\section{Initial Analyses}

Consistent with previous results (Fetterman \& Robinson, 2013), a greater proportion of women (60\%), relative to men (37\%), located themselves in the heart, $\chi^{2}(602)=30.43, p<.001$. Additionally, and in concert with our broad emphasis on intuitive thinking processes, women reported greater religiosity $(M=3.95)$ than men $(M=3.60)$ did, $F(1,601)=7.13, p=.008, \eta_{\mathrm{p}}^{2}=$ .01 , with similar differences emerging for the other religiosity items, $p s<.10$. Given these results, we will control for participant sex in follow-up analyses.

\section{Are Heart-Locators More Religious?}

A key hypothesis was that self-locations would provide insight into religious beliefs. To examine this idea, we conducted four one-way ANOVAs. As hypothesized, religiosity was appreciably higher among the heart group $(M=4.15)$ than the head group $(M=3.43), F(1,601)$ $=32.57, p<.001, \eta_{\mathrm{p}}^{2}=.05$. We next turned to the self-centrality and importance measures. Heart-locators $(M=4.04)$, relative to head-locators $(M=3.26)$, reported that religious beliefs were more central to the conduct of their lives, $F(1,601)=37.16, p<.001, \eta_{\mathrm{p}}{ }^{2}=.06$, and they also rated their religious beliefs as more important to them (head group $M=3.30$; heart group $M$ $=4.02), F(1,601)=34.65, p<.001, \eta_{\mathrm{p}}^{2}=.06$. Finally, heart-locators characterized themselves as more spiritual $(M=4.65)$ than head-locators $(M=4.05), F(1,601)=18.79, p<.001, \eta_{\mathrm{p}}^{2}=$ .03. These results provide consistent support for the idea that an embodied self perspective has merit in understanding religious beliefs. 
Given that there were sex differences in both self-location and religious beliefs, we followed up the ANOVAs reported above with four multiple regressions in which self-location (1 = head; +1 = heart $)$ and participant sex (-1 = male; +1 = female) were simultaneously regressed. Results for these analyses, which are reported in Table 1, reveal that self-location was the stronger predictor when controlling for overlapping variance. Indeed, sex differences in religiosity could be ascribed to sex differences in self-location, in that sex differences in religiosity became non-significant with self-locations controlled.

\section{Discussion}

Whereas some people think the self is in the head or brain, others are fairly certain it is in the heart (Adam et al., 2015). Consistent with the results of Fetterman and Robinson (2013), these were somewhat equally-sized groups of people, with heart-locations also being more prevalent among women than men. Of greater novelty, self-location was a robust predictor of religiosity. Heart-locators were more religious than head-locators and they ascribed greater importance to religious beliefs in their lives. They were also more spiritual. These differences could not be ascribed to biological sex, which in fact appeared to be the weaker predictor of religious beliefs. Altogether, Study 1 provided preliminary support for our key predictions.

Before attempting to replicate Study 1, some brief points should be made. The average head-locator should be viewed as less religious than the average heart-locator rather than atheistic. We say this both because atheism is rare (Bishop, 1999) and because we did not assess it. In addition, metaphors for the head versus the heart seem to be primarily used in the context of religious beliefs rather than more nebulous forms of spirituality (Swan, 2009). For this reason, and because spirituality typically occurs in the context of religious beliefs (Batson et al., 1993), religion-related measures constitute the core outcomes of Studies 2-5. 


\section{Study 2}

There are some unique factors that could affect the religious lives of college students relative to the general population. Accordingly, the key purpose of Study 2 was to conceptually replicate the results of Study 1 in a sample that was more diverse with respect to age as well as occupation and geographical location. We could accomplish this by recruiting participants through Amazon's Mechanical Turk (AMT), which results in sample diversity of the desired types with equally reliable data (Buhrmester, Kwang, \& Gosling, 2011). In this sample, too, we expected heart-locators to be more religious than head-locators.

\section{Method}

\section{Participants and Procedures}

One of the goals of the investigation was to replicate key results across labs and modes of data collection. Accordingly, Study 2 was conducted by the second author using Amazon's Mechanical Turk (AMT) resource. This allowed us to obtain a sample more diverse with respect to age and geographic location than in Study 1. Participants were eligible for the study if they were over 18 years old and living in the United States. The self-location and religiosity measures were embedded in a series of unrelated tasks pursuant of other research questions. The final sample consisted of 346 (159 female) participants whose average age was 36.20 (SD = 13.08; range $=18-79)$ and participants received $\$ 0.50$ for completing the very brief survey.

\section{Measures}

Self-location. Participants indicated whether they locate the self primarily in the head or the heart, using the same measure administered in Study 1. Somewhat unexpectedly, the sample contained a greater proportion of head-locators (70\%) than heart-locators (30\%). This difference cannot be attributed to the use of AMT because Study 5 also used this resource and responses to 
the self-location question were more evenly split in Study 5. In any case, sample proportions will vary somewhat naturally and the key question is one of individual differences.

Religiosity. Study 2 targeted religiosity using a single item with a high degree of face validity (Zuckerman, 2007). Specifically, participants answered the question "How religious are you?" with a rating along a 6-point scale $(1=$ not very religious; $6=$ very religious; $M=2.55 ; S D$ =1.81). The item was adapted from Norenzayan and Hansen (2006).

\section{Results}

\section{Initial Analyses}

Replicating Study 1, a greater percentage of women (48\%) than men (18\%) located the self in the heart, $\chi^{2}(346)=30.15, p<.001$. Also replicating Study 1 , women scored higher in religiosity $(M=2.96)$ than men $(M=2.20), F(1,345)=16.01, p<.001, \eta_{\mathrm{p}}{ }^{2}=.04$.

\section{Are Heart-Locators More Religious?}

We expected heart-locators to be more religious than head-locators. This hypothesis was confirmed in a one-way ANOVA (heart $M=3.13$ versus head $M=2.30), F(1,345)=15.67, p<$ $.001, \eta_{\mathrm{p}}^{2}=.04$. In addition, the head/heart $(-1 /+1)$ predictor continued to predict religiosity, $t=$ 3.00, $p=.003$, Beta $=.16$, with participant sex, $t=2.87, p=.004$, Beta $=.16$, also controlled in a multiple regression. These results replicate Study 1 among an older sample.

\section{Discussion}

Previous self-location studies have involved traditional-aged college students. It was therefore not certain that self-location would function similarly among older adults or those from other areas of the country. The results of Study 2 provide an affirmative answer to this question. Although the proportion of head-locators was higher in Study 2 than in Study 1 (but not in Study 5, which also used AMT), heart-locators were again more religious people. We therefore 
emphasize the manner in which the Study 2 results replicate and extend those of Study 1 among a sample that was more diverse with respect to age and geographic location.

\section{Study 3}

Psychologists have been centrally interested in how people could believe in God despite the lack of direct empirical evidence (Atran \& Norenzayan, 2004; Bering, 2006). In Study 3, we sought to turn toward this question by directly asking about belief in God. In addition, we sought to provide cross-cultural evidence for the manner in which self-location functions. Toward this end, we conducted a study in Germany rather than the United States.

\section{Method}

\section{Participants and Procedures}

Because the same key measures were administered to three samples in Tübingen, Germany, we combined them into one larger pool of 312 (194 female). This group primarily consisted of university students, but also included some non-student area residents as well, resulting in some degree of diversity with respect to age $(M=29.98 ; S D=7.46)$. The selflocation and belief in God measures were embedded in larger investigation-independent protocols, which effectively disguised the present hypotheses.

\section{Measures}

Self-location. The self-location question was translated into German, with the response options “gehirn” (brain) versus "herz" (heart). As in the United States (Fetterman \& Robinson, 2013), an approximately equal number of Germans placed the self in the head (51\%) versus the heart $(49 \%), \chi^{2}(312)=0.63, p=.428$.

Belief in God. Studies 1 and 2 had asked about religious beliefs somewhat generally. In Study 3, we sought to ask a more targeted question that gets to the core of religious belief 
(Bishop, 1999). Specifically, participants in Study 3 were asked (in German) “To what extent do you believe in a God?” (Fetterman, 2016), a question they answered using a 6-point scale (1 = not at all; 6 = fully and completely). Responses to this measure correlate highly with other measures of religious belief and faithfulness (Büssing, 2012). As a point of interest, the German sample believed in God, on average, to a lesser extent $(M=2.98$; $S D=1.52)$ than did the American sample of Study $4(M=4.82$; $S D=1.53), F(1,1526)=363.03, p<.001, \eta_{\mathrm{p}}^{2}=.19$. Such differences are often observed in US/European comparisons (Zuckerman, 2007).

\section{Results}

\section{Initial Analyses}

There were some apparent cultural differences with respect to gender. Although sex differences in self-location are fairly robust in American samples (Fetterman \& Robinson, 2013), the proportion of German males who were heart-locators (43\%) did not differ from the proportion of German females who were heart-locators $(49 \%), \chi^{2}(312)=0.30, p=.582$. Belief in God similarly did not vary by sex, $F(1,310)=1.57, p=.211, \eta_{\mathrm{p}}^{2}=.00$.

\section{Do Heart-Locators Believe in God to a Greater Extent?}

Group differences in self-location operated similarly in the German sample in that heartlocators believed in God $(M=3.30)$ to a greater extent than head-locators $(M=2.69), F(1,310)$ $=12.72, p<.001, \eta_{\mathrm{p}}^{2}=.04$. Thus, a central tenet of religiosity (Bishop, 1999; Zuckerman, 2007) - namely, belief in God - systematically varied by self-location. In a follow-up multiple regression, the location/God belief relationship remained significant, $t=3.61, p<.001$, Beta $=$ .20 , when controlling for participant sex (female scored higher), $t=-1.39, p=.166$, Beta $=-.08$.

\section{Discussion}


Conceptual metaphors are those that track thought primarily and language secondarily (Lakoff \& Johnson, 1999). Cross-cultural investigations will be a useful tool in this context, particularly when different languages are involved, as cultural differences could occur with respect to some metaphors (Gilead, Gal, Polak, \& Cholow, 2014). On the basis of such considerations, we emphasize the continuity of the results across the first three studies. As in the first two studies, people who located the self in the heart tended toward greater religiosity (in the form of beliefs in God) even though the relevant questions were asked in German rather than English. Further cross-cultural examinations could be useful, though.

\section{Study 4}

Fetterman and Robinson (2013) showed that self-location predicted some outcomes when controlling for personality traits and its pattern of correlates across studies was unique to the personality literature. Nonetheless, no prior studies have focused on the religious domain and it may therefore be useful to control for personality traits in the present context. Agreeableness is a modest predictor of religious beliefs and extraversion can predict them to some extent (Saraglou, 2002). We therefore controlled for these traits, as well as neuroticism, in a Study 4 analysis.

Perhaps of more importance, Study 4 focused on questions of mechanism. Heart-locators, we propose, are likely to rely on intuition and sentiment in matters of morality or moral judgment. As a result of this warmth-infused (Fetterman \& Robinson, 2013) experiential style, relative to one that is more intellectual, heart-locators should tend toward greater religiosity in the context of less questioning. This analysis suggests that emotion-related tendencies toward moral concern - or empathetic concern (Jack et al., 2016) - may partially mediate the relationship between self-location and belief in God. 
Such ideas can be tested using moral dilemmas that pit an intuitive-emotional style of moral cognition against a rational-utilitarian style (Greene, 2011). Briefly, the dilemmas are such that one would have to engage in a repugnant, hurtful act (e.g., kill someone) to save the greatest number of people. To the extent that moral decisions are made on the basis of empathetic concern, such hurtful actions should be avoided (Bartels \& Pizarro, 2011; Conway \& Gawronski, 2013). Conversely, a cold, analytical manner of approaching the problems can favor such actions, even when they involve intentional harm (Paxton, Ungar, \& Greene, 2012). Altogether, we hypothesized that heart-locators would approach moral dilemmas with a more intuitive, empathetic style and that tendencies of this type might prove explanatory in accounting for their stronger beliefs in God, given robust links of the latter type (Jack et al., 2016).

\section{Method}

\section{Participants and Procedures}

A large group of 1216 participants completed the self-location and belief in God measures in the context of studies pursing other research questions. ${ }^{1}$ We had participant sex information for 1084 of these participants (553 female; $M$ age $=19.59$ ), measures of the affectrelevant traits of extraversion, neuroticism, and agreeableness from 1081 of them, and dilemma response data from 116. Accordingly, different analyses are based on different subsets of the total sample. The measures were completed on personal computers in a laboratory and the undergraduate participants received psychology course credit.

\section{Measures}

Self-location. The measure of self-location was identical to Study 1. In Study 4, there were more heart-locators (54\%) than head-locators (46\%), though the percentages were not that discrepant from a 50/50 split. 
Belief in God. Participants were asked to rate the strength of their beliefs in God ("To what extent do you believe in a God?”: Fetterman, 2016) using a 6-point scale (1 = not at all; 6 = fully and completely). The average degree of belief was higher among these Americans than among the Germans of Study $3(M=4.82 ; S D=1.53)$.

Affect-Relevant Traits. We deemed it useful to establish discriminant validity with respect to the affect-relevant (Robinson, 2007) traits of extraversion, neuroticism, and agreeableness. To do so, we administered Goldberg’s (1999) reliable and valid (John \& Srivastava, 1999) Big Five measures of extraversion (10 items: e.g., “don’t mind being the center of attention”; $M=3.45 ; S D=0.83$; alpha = .90), neuroticism (10 items: e.g., "worry about things"; $M=2.68 ; S D=0.82$; alpha = .88), and agreeableness (10 items: e.g., "am interested in people”; $M=4.12 ; S D=0.61$; alpha = .86). All items were rated in terms of how well they describe the self $(1=$ very inaccurate; 5 = very accurate $){ }^{2}$

Empathetic Moral Concern. According to prominent metaphors, the head solves moral problems through reasoning, whereas the heart follows intuition and feeling (Swan, 2009). To capture dynamics of this type, Study 4 administered 5 classic moral dilemmas in which a cold form of rationality is pitted against an empathetic form of emotionality (Gleichgerrcht \& Young, 2013). Specifically, the dilemmas were such that the self could save the greatest number of people only by engaging in a hurtful action. Empathetic responding should disfavor such actions, despite their rationality (Greene, 2011). As an example, consider the following scenario:

You are an inmate in a concentration camp. A sadistic guard is about to hang your son who tried to escape and wants you to pull the chair from underneath him. He says that if you don’t he will not only kill your son but some other innocent 
inmate as well. You don't have any doubt that he means what he says. What would you do?

For this scenario, the cold, rational response was "I would pull the chair" whereas the warm, emotional response was "I would NOT pull the chair". Participants had to indicate which of the two responses they would more likely make. The other scenarios were structurally parallel, but in the context of other dire circumstances (e.g., a runaway trolley). A total score was computed by scoring rational responses as 0 , empathetic responses as 1 , and averaging across scenarios $(M=0.52 ; S D=0.25)$. Note that these choices were somewhat evenly split.

\section{Results}

\section{Initial Analyses}

A higher percentage of women (63\%), relative to men (46\%), located the self in the heart, $\chi^{2}(1084)=30.16, p<.001$. Women also reported higher beliefs in God (male $M=4.64$; female $M=4.98), F(1,1082)=13.96, p<.001, \eta_{\mathrm{p}}^{2}=.01$.

\section{Do Heart-Locators Believe in God to a Greater Extent?}

An ANOVA revealed that belief in God was higher among heart-locators $(M=5.12)$ than head-locators $(M=4.47), F(1,1214)=57.31, p<.001, \eta_{\mathrm{p}}{ }^{2}=.05$. Furthermore, self-location $(-1$ $=$ head; $+1=$ heart) continued to predict belief in God, $t=6.31, p<.001$, Beta $=.19$, with participant sex $(-1=$ male; $+1=$ female $), t=2.62, p=.009$, Beta $=.08$, controlled.

\section{Controlling for Personality}

Extraversion and agreeableness predict religiosity to some extent (Saraglou, 2002). Similarly, we found positive relationships between agreeableness and belief in God, $r=.18, p<$ .001 , as well as between extraversion and belief in God, $r=.06, p=.055$. Neuroticism was unrelated to belief in God, $r=.00, p=.907$. 
It is also informative to consider the personality profile of self-location. As expected, heart-locators scored higher in agreeableness $(M=4.25)$ than head-locators $(M=3.98)$, as indicated by a between-groups ANOVA, $F(1,1079)=54.36, p<.001, \eta_{\mathrm{p}}{ }^{2}=.05$. However, heart-locators also scored higher in extraversion (head $M=3.38$; heart $M=3.50), F(1,1079)=$ $5.40, p=.020, \eta_{\mathrm{p}}^{2}=.01$, and (to a small extent) neuroticism (head $M=2.62$; heart $M=2.72$ ), $F$ $(1,1079)=4.17, p=.040, \eta_{\mathrm{p}}^{2}=.00$. Thus, while heart-locators were more agreeable than headlocators, they were also broadly emotional as well. Even so, self-location $(-1=$ head; $+1=$ heart $)$ remained a robust predictor of belief in God, $t=5.55, p<.001$, Beta $=.17$, with extraversion, $t=$ 0.25, $p=.800$, Beta $=.01$, agreeableness, $t=4.52, p<.001$, Beta $=.14$, and neuroticism, $t=$ $0.49, p=.621$, Beta $=.02$, controlled in a multiple regression.

\section{Mediation by Moral Concern}

Heart-locators may believe in God to a greater extent because they are more prone to empathetic moral thinking. To investigate this possibility, we used Hayes’ (2013) SAS-based PROCESS macro, which employs bootstrapping procedures to examine the possibility of mediated relationships. The models were estimated with 5,000 bootstrapped samples and variables were standardized to aid interpretation.

In Model 1, self-location (-1 = head; +1 = heart) predicted empathy-based moral decisions, the proposed mediator, $t=2.94, p=.004$, Beta $=.27$. In Model 3, self-location predicted belief in God, the outcome variable, $t=7.57, p<.001$, Beta $=.21$. In Model 2, both self-location, $t=2.10, p=.038$, Beta $=.19$, and empathetic moral concern, $t=3.05, p=.003$, Beta $=.28$, were significant predictors of God belief, consistent with a mediational pathway.

To determine whether there was significant mediation, PROCESS computed a 95\% biascorrected confidence interval (BCCI) for the mediated or indirect pathway from self-location to 
Self-Location and Religiosity 21

empathetic moral concern to belief in God. The mean estimate for this indirect pathway (ab) was .0758 and the 95\% BCCI was .0268 to .1680. Because the BCCI excluded 0, we can conclude that empathetic moral thinking was a significant mediator (Hayes, 2013). That is, heart-locators are predisposed to believe in God in part because they are predisposed to intuitive, feeling-based thinking when making decisions concerning matters of morality. For comparison purposes, the 95\% BCCI for the unmediated pathway (c') also excluded 0 (.0115 to .3828), indicating the likelihood of additional mediators (MacKinnon \& Fairchild, 2009).

\section{Discussion}

Studies 1 and 2 had established that heart-locators are more religious than head-locators. Studies 3 and 4 extended this analysis by showing that heart-locators are higher in a core aspect of religiosity - namely, the belief in a supernatural God (Atran \& Norenzayan, 2004; Bering, 2006). Furthermore, Study 4 showed that the latter relationship could not be ascribed to Big 5 personality traits. Thus, self-location is both a novel and robust predictor of individual differences in religious belief.

Further, Study 4 showed that a feeling-based approach to moral decisions mediated the relationship between self-location and the magnitude of beliefs in God. That is, heart-locators appear more likely to approach moral problems in an intuitive, feeling-based manner (Conway \& Gawronski, 2013) and this thinking style in part contributes to their tendency toward supernatural beliefs. Or, stated another way, head-locators are more likely to approach moral problems in a cold, utilitarian way (Greene, 2011) and this controlled form of moral cognition is less conducive to strong beliefs in God (Szekely, Opre, \& Miu, 2015). The mediation was not complete, however, indicating that there are other reasons, too, why heart-locators are more faithful than head-locators. Study 5 sought to extend this analysis. 


\section{Study 5}

To "follow one's heart" means to follow one's intuitions whereas to "use one's head" means to think carefully. These differences seem likely to be manifest in different thinking styles - more intuitive in the first case and more rational in the second (Epstein, 2003). To examine this possibility in a new way within a fifth study, we administered the Cognitive Reflection Test (CRT), which was designed in such a way that relying on intuition results in predictable errors (Frederick, 2005). As a result of such features, one can use the CRT to quantify cognitive styles that favor intuition versus reflection (Baron, Scott, Fincher, \& Emlen Metz, 2015). Intuitive responders on the CRT are lower in need for cognition and they are more susceptible to a number of heuristics and biases that occur when people do not correct for their initial feelings or hunches (Baron et al., 2015; Frederick, 2005).

Of additional pertinence, studies have shown that the CRT predicts belief in God such that more intuitive responders on the CRT believe in God to a greater extent (Gervais \& Norenzayan, 2012; Shenhav et al., 2012). Manipulations of intuition versus reflection result in similar effects (Gervais \& Norenzayan, 2012) and the relationship tracks active preferences rather than passive socialization processes (Shenhav et al., 2012). Given these results, it is plausible that intuitive responses to the CRT may play some role in mediating the relationship between self-locations and belief in God. This mediation is likely to be partial, though, in part because the CRT/belief relationship is moderate in effect size (Gervais \& Norenzayan, 2012).

\section{Method}

\section{Participants and Procedures}

The Study 5 sample consisted of 99 (45 female) participants recruited through Amazon’s Mechanical Turk. They completed the study online and received \$0.50 in compensation. Owing 
to the recruitment method, the sample was more diverse with respect to age $(M=31.61 ; S D=$ 8.53) and geographic location than was true in Study 4. The self-location and God belief measures were embedded in other tasks unrelated to the purposes of the current study. Tasks and/or measures were randomized across participants to preclude systematic order effects.

\section{Measures}

Self-location. Participants answered the same self-location question administered in Study 1. Relatively equal-sized groups located the self in the head (54\%) versus the heart (46\%).

Belief in God. Participants were presented with the same belief in God question given in Study 4 (Fetterman, 2016; $M=3.41 ; S D=1.55$ ).

Cognitive Reflection Test. To assess intuitive thinking outside of the context of moral decision-making, we used the Cognitive Reflection Test (CRT: Frederick, 2005), which places people along an intuitive versus reflective thinking style continuum in a reliable and valid manner (Frederick, 2005; Shenhav et al., 2012). The test specifically consists of 3 math problems designed in such a way that they pull for an intuitive answer that, upon further reflection, turns out to be wrong. Intuitive people give intuitive answers and reflective people give correct answers (Frederick, 2005). As an example, one problem reads: “A bat and a ball cost \$1.10 in total. The bat costs $\$ 1.00$ more than the ball. How much does the ball cost (in cents)?” Participants received a 0 if they gave the correct response of 5 cents and a 1 if they gave the intuitive response of 10 cents. These scores were averaged across items $(M=0.54 ; S D=0.43)$.

\section{Results}

\section{Initial Analyses}

In this sample, the percentages of men (47\%) and women (46\%) who located the self in the heart were equal, $\chi^{2}(99)=0.00, p=.97$. In Study 5, also, men and women believed in God to 
the same extent, $F(1,98)=.09, p=.768$, and sex differences on the CRT were not apparent, $F$ $(1,98)=.001, p=.977$

\section{Do Heart-Locators Believe in God to a Greater Extent?}

We hypothesized that heart-locators would believe in God to a greater extent. This hypothesis was confirmed in a between-groups ANOVA (head $M=2.85$; heart $M=4.04$ ), $F(1$, $98)=17.33, p<.001, \eta_{\mathrm{p}}^{2}=.15$. In addition, the relationship remained significant, $t=4.04, p<$ .001 , Beta $=.38$, when controlling for participant sex, $t=0.30, p=.762$, Beta $=.03$.

\section{Mediation by Intuitive Thinking}

Study 4 found that intuitive thinking within the moral domain (Greene, 2011) mediated the relationship between self-location and belief in God. In Study 5, we sought to examine the generality of this sort of model by using the CRT as a measure of non-moralistic intuitive thinking (Frederick, 2005). As in Study 4, mediation analyses were conducted using Hayes’ (2013) PROCESS macro and its bootstrapping procedures.

In Model 1, self-location (-1 = head; +1 = heart) predicted intuitive thinking on the CRT, the proposed mediator, $t=2.10, p=.038$, Beta $=.21$. That is, heart-locators were more prone to intuitive thinking by this objective measure. Model 3 replicated the ANOVA reported above, in that self-location predicted belief in God, $t=4.16, p<.001$, Beta $=.39$. Model 2, finally, established that both self-location, $t=3.65, p<.001$, Beta $=.34$, and intuitive thinking, $t=2.57$, $p=.012$, Beta $=.24$, predicted belief in God, suggesting partial mediation

To determine whether the mediational pathway involving CRT responses was significant, we turned to the BCCI results. The mean estimate for the indirect pathway $(a b)$ was .0492 and the $95 \%$ BCCI was .0065 to .1322 . These results indicate that intuitive thinking mediated the self-location/belief relationship (Hayes, 2013). On the other hand, the 95\% BCCI for the 
unmediated pathway ( $\left.c^{\prime}\right)$ was .1540 to .5203 , indicating that other factors - like empathetic concern (Study 4) - are also important to consider in understanding the present relationships.

\section{Discussion}

Consistent with metaphors for the head versus the heart (Swan, 2009), we found that heart-locators received more intuitive scores on the CRT (Frederick, 2005). This perspective on self-location suggests that it may predict other outcomes linked to intuition versus reflection such as susceptibility to heuristics and biases (Frederick, 2005). In the present context, though, we used this link to explore the possibility that intuitive thinking on the CRT might mediate the relationship between self-location and belief in God, particularly given previous evidence for a CRT/belief link (e.g., Shenhav et al., 2012). A mediational pathway of this type was found. Thus, a tendency toward intuitive thinking does in part mediate the relationship between selflocation and belief in God. However, heart-locators also believe in God for other reasons, among them a tendency toward empathetic moral thinking (Study 4). In sum, there are likely to be several reasons why self-location is a robust predictor of religion-related beliefs.

\section{General Discussion}

The location of the self in the body has intrigued both philosophers (Clark, 1999) and laypeople (Swan, 2009) for centuries. Aristotle (trans. 2001) was pretty sure that the self was in the heart, whereas Plato (trans. 1987) was pretty sure that it was in the head. Similarly, while most people believe that the self has a primary location, they disagree on that location (Alsmith \& Longo, 2014). Some people identify the head as the primary locus of the self and others identify the heart (Adam et al., 2015; Limanowski \& Hecht, 2011). Fetterman and Robinson (2013) proposed that these individual differences both follow from, and reinforce, conceptual metaphors linking the head to logic/rationality and the heart to feeling/intuition (Lakoff \& 
Johnson, 1999). Support for this idea was found in terms of traits ascribed to the self, such as in the domain of agreeableness (Fetterman \& Robinson, 2013).

Self-locations, though, should affect more than what people believe about themselves. Specifically, if heart-locators truly do rely on feelings and intuition to a greater extent, then they should be more prone to beliefs that follow from such intuitive ways of thinking. The present investigation used such ideas to make predictions concerning individual differences in religiosity. Because religious beliefs partially follow from intuition (Baumard \& Boyer, 2013), heart-locators should tend toward greater religiosity. By contrast, because rational evidence does not provide a strong basis for religious beliefs (Van Leeuwen, 2014), head-locators should tend toward lesser religiosity. Study 1 provided initial evidence for this novel set of predictions in that heart-locators had stronger religious beliefs than head-locators did. Study 2 replicated such differences in an older sample and Study 3 replicated them in another country. And Studies 4 and 5 showed that relationships of this type were partly mediated by intuitive thinking styles, whether within the moral domain (Study 4) or not (Study 5). In the General Discussion, we develop the implications of the findings while presenting potential directions of research.

\section{Implications}

Conceptual metaphors (e.g., SWEET IS NICE) are shared both within and across cultures (Kövecses, 2005). Perhaps because this is true, the primary sources of support for CMT have involved experimental methods and it has been uncertain whether CMT provides insights into personality process (Landau et al., 2010). This is unfortunate because a powerful theory like CMT should, in principle, be capable of generating individual difference predictions (Robinson \& Fetterman, 2014). In this connection, the present findings join a handful of studies that have successfully applied CMT to the individual difference realm. 
In fact, the self-location measure works because of, rather than in spite of, people agreeing on the metaphoric features of the head (e.g., it operates by logic) versus the heart (e.g., it operates according to feelings). People think that they are in their heads when they interact with the world in head-like ways (e.g., they are rational) and in their hearts when they interact with the world in heart-like ways (e.g., they follow their feelings). In other words, head-heart metaphors (Swan, 2009; Yu, 2003) both capture and reinforce individual differences in preferred ways of interacting with the world, whether rational or experiential (Epstein, 2003).

Along these lines, Fetterman and Robinson (2013) proposed that heart-locators, relative to head-locators, are more likely to base their beliefs on feelings and intuition. The present findings provide the strongest extant evidence for this point in that beliefs in God, to a considerable extent, follow from feelings and intuitions (Bering, 2006; Gervais \& Norenzayan, 2012) and we showed that heart-locators believe in God to a greater extent. Moreover, we showed that intuitive thinking styles - both in the form of empathetic moral concern (Conway \& Gawronski, 2013) and intuitive decision-making (Frederick, 2005) - mediate head-heart differences in religious belief. Thus, heart-locators are more likely to follow their feelings and this, in part, contributes to their higher levels of faith. Such mediation results, we think, provide a valuable window on individual differences in self-location and how they operate.

In this connection, the head-heart distinction seems to share some affinity with dualprocess models of thinking (Evans, 2008) and their relevant individual differences (Frederick, 2005). By this account, heart-locators would be “system 1" thinkers or those that like to rely on intuition when solving presented problems. By contrast, heart-locators would be "system 2" thinkers or those that more carefully scrutinize their answers before responding (Evans, 2008). 
Study 5 offered the first direct evidence of this type in that heart-locators solved the problems of the Cognitive Reflection Test (CRT: Frederick, 2005) in a more intuitive (but incorrect) manner. However, the correlation between self-location and the CRT was moderate rather than large $(r=.21)$. This suggests that the head-heart distinction should not be equated with the system 1-system 2 distinction. Indeed, a dual-process perspective on self-location might lead one to believe that heart-locators are more impulsive. We have not found this to be the case, however. Furthermore, there is evidence that heart-locators are more, rather than less, thoughtful about their emotions and, potentially, their personal relationships (Adam et al., 2015; Fetterman \& Robinson, 2013). Thus, while a dual-process perspective captures some features of the headheart distinction, it does not capture all of them. The same can be said of religiosity.

Even so, the individual differences that we have highlighted would seem to possess implications for the manner in which religious beliefs are held. Heart-locators were more certain concerning their religious beliefs and they thought they were more important (e.g., central to daily living). Furthermore, given that the heart's currency is affect rather than reason (Lakoff \& Johnson, 1999; Swan, 2009), one might expect the religious beliefs of heart-locators to have a more consequential affective basis, which should strengthen them while rendering them resistant to change (Petty, Fabrigar, \& Wegener, 2003). By contrast, given the head's transactions in reason and rationality (Lakoff \& Johnson, 1999), one might expect head-locators to be more responsive to reason (Van Leeuwen, 2014) and evidentiary conflicts (Pennycook, Cheyne, Barr, Koehler, \& Fugelsang, 2014) when making decisions about their religious beliefs (Shenhav et al., 2012), or about the existence of God (Atran \& Norenzayan, 2004).

Several components of this analysis merit future attention. To the extent that one could disentangle affective and cognitive factors in religious belief, doing so would seem highly 
pertinent to the head-heart distinction in that affective factors, in particular, should distinguish head-locators from heart-locators. As an example, intrinsic motivations for religious belief are likely to be stronger among heart-locators, whereas extrinsic considerations could figure more prominently in the religious beliefs of head-locators (Lowicki \& Zajenkowski, 2017). In addition, the idea that the religious beliefs of heart-locators should be more resistant to change could be assessed within longitudinal research or perhaps within paradigms in which arguments are used to challenge the rational basis for religious belief systems (Petty et al., 2003). If we are correct, heart-locators should be more resistant to such arguments.

\section{Additional Questions, Limitations, and Future Directions}

Self-location, we believe, captures features of both embodiment and metaphor. Selflocations are embodied in the sense that people identify the self with particular regions of the body (Limanowksi \& Hecht, 2011) and some of the effects of self-location may follow from such processes (Robinson \& Fetterman, 2014). Self-locations are metaphoric, however, in that the functions ascribed to the head and the heart - and particularly the heart (Swan, 2009) - are metaphoric in nature (Lakoff \& Johnson, 1999). One cannot “follow one’s heart” in any literal sense, for example, because the heart cannot prescribe courses of belief or action. Thus, selflocations predict the outcomes that they do because of metaphoric associations.

Self-locations probably predispose people to religious beliefs rather than vice versa.

Whether one is a head person or a heart person captures core features of the person (Fetterman \& Robinson, 2013) that favor logic and rationality (head people) or feelings and intuition (heart people). Such differences, in turn, lead people to approach religious belief as a matter of faith (heart people) or reasonable doubt (head people). By contrast, it seems less likely that religiosity, 
per se, would influence the perceived location of the self (Wink, Ciciolla, Dillon, \& Tracy, 2007). Of course, further longitudinal research would be necessary to fully evaluate these ideas.

Our analysis focused on religious beliefs, but self-locations should matter in ways beyond those documented. For example, one can view God as a stern disciplinarian or as a loving, caring, almost maternal figure (DesCamp \& Sweetser, 2005). The latter viewpoint is more consistent with metaphors for the heart (Swan, 2009) and we suspect that heart-locators would be more likely to endorse this perspective of the creator. Study 4 showed that heart-locators were less willing to harm one person to save others (Greene, 2011). It is likely that this intuitive style of moral thinking would extend to other forms of moral thinking, such as less favorable attitudes toward taboo but harmless behaviors (Haidt, 2013).

Turning to a different point, we found that head-heart metaphors seem to function similarly in Germany and the United States. Moreover, the heart seems to be linked to faithfulness in both Christian and non-Christian religions (Swan, 2009). However, the processes could work differently in Asian cultures. Asian cultures, relative to Western cultures, are more likely to value intuition over logic (Buchtel \& Norenzayan, 2008). Furthermore, these differences in thinking style seem to have a parallel in self-locations in that the heart (at least in China) is given a broader scope of metaphoric powers (Yu, 2003). Thus, it would be valuable to study self-locations in Asian as well as Western cultures.

Other directions relate to the exact sorts of processes that vary by self-location. We have suggested that head-locators value rationality and heart-locators value their feelings, which maps onto Epstein’s (2003) distinction between the rational and experiential thinking systems. However, other system-like distinctions also have merit. For example, Baron-Cohen and colleagues (e.g., Baron-Cohen, Knickmeyer, \& Belmonte, 2005) have contrasted systematizing 
tendencies, which are typically applied to inanimate systems (e.g., physics), with empathizing tendencies, which concern themselves with the feelings and wishes of animate objects. And Jack and colleagues (e.g., Jack et al., 2013) have contrasted two neural networks, one of which tends to focus on cognitive tasks and how to accomplish them and the other of which plays an important role in social cognition. It would be useful to forge more explicit ties between selflocation and these other sorts of processing frameworks, which somewhat directly follow from neuroscientific considerations (also see Lieberman \& Eisenberger, 2005).

With respect to the Jack et al. (2013) framework and its subsequent developments, we can say more. Jack et al. (2016) distinguish analytical thinking from empathetic concern and link them to the neural networks of Jack et al. (2013). The preferred thinking style of head-locators is likely to be analytic, much as Jack et al. (2016) describe. Also, the preferred thinking style of heart-locators (experiential \& warm) should result in empathetic concern. If so, empathetic concern should mediate the relationship between heart-location and religious belief. The results of Study 4 seem consistent with this analysis though further research could also be useful. In this connection, Jack et al. (2016) note that empathetic concern (or perhaps moral concern more broadly) can be operationalized in different ways and some of them may be quite relevant to understanding the divergent thinking styles that we have highlighted.

As a final set of points, we have shown that heart-locators possess stronger religious beliefs. Similarly, heart-locators may be prone toward stronger beliefs in other areas in which affective and motivational factors play a primary role, such as political ideology (Jost, 2006). Additionally, the epistemic style of heart-locators could discourage them from domains in which intellectual pursuits figure prominently. In support of this point, Fetterman and Robinson (2013) found that heart-locators had lower GPAs and there is evidence for the idea that religious 
individuals seem to avoid professions - like science or higher education - in which reason and rationality constitute the basis of knowledge evaluation (Rios, Cheng, Totton, \& Shariff, 2015). Such dynamics could be particularly strong among heart-locators relative to head-locators.

\section{Conclusions}

Conceptual metaphors for the head versus the heart contrast very different modes of decision-making. These metaphors can provide insight into personality by asking people whether the self primarily resides in the head or the heart (i.e., self-location). Consistent with metaphors linking the heart to feelings, and to intuition, we found that heart-locators, relative to headlocators, were more religious and believed in God to a greater extent. These findings significantly extend our knowledge of the metaphor-personality interface. 


\section{References}

Adam, H., Obodaru, O., \& Galinsky, A. D. (2015). Who you are is where you are: Antecedents and consequences of locating the self in the brain or the heart. Organizational Behavior and Human Decision Processes, 128, 74-83.

Alsmith, A. J. T., \& Longo, M. R. (2014). Where exactly am I? Self-location judgements distribute between head and torso. Consciousness and Cognition, 24, 70-74.

Argyle, M., \& Beit-Hallahmi, B. (1975). The social psychology of religion. London, England: Routledge and Kegan Paul.

Aristotle (2001 trans.). The basic works of Aristotle (R. McKeon, Trans.). New York, NY: Random House.

Atran, S., \& Norenzayan, A. (2004). Religion’s evolutionary landscape: Counterintuition, commitment, compassion, communion. Behavioral and Brain Sciences, 27, 713-770.

Baron, J., Scott, S., Fincher, K., \& Emlen Metz, S. (2015). Why does the Cognitive Reflection Test (sometimes) predict utilitarian moral judgment (and other things)? Journal of Applied Research in Memory and Cognition, 4, 265-284.

Baron-Cohen, S., Knickmeyer, R. C., \& Belmonte, M. K. (2005). Sex differences in the brain: Implications for explaining autism. Science, 310, 819-823.

Bartels, D. M., \& Pizarro, D. A. (2011). The mismeasure of morals: Antisocial personality traits predict utilitarian responses to moral dilemmas. Cognition, 121, 154-161.

Batson, C. B., Schoenrade, P., \& Ventis, M. L. (1993). Religion and the individual: A socialpsychological perspective. New York, NY: Oxford University Press.

Baumard, N., \& Boyer, P. (2013). Religious beliefs as reflective elaborations on intuitions: A modified dual-process model. Current Directions in Psychological Science, 22, 295-300. 
Bering, J. M. (2006). The cognitive psychology of belief in the supernatural. In: P. McNamara (Ed.), Where God and science meet: How brain and evolutionary studies alter our understanding of religion (Vol. 1, pp. 138-148). Westport, CT: Praeger Publishers.

Bishop, G. (1999). Trends: Americans’ belief in God. The Public Opinion Quarterly, 63, 421434.

Buchtel, E. E., \& Norenzayan, A. (2008). Which should you use, intuition or logic? Cultural differences in injunctive norms about reasoning. Asian Journal of Social Psychology, 11, 264-273.

Buhrmester, M., Kwang, T., \& Gosling, S. (2011). Amazon’s Mechanical Turk: A new source of inexpensive, yet high-quality, data? Perspectives on Psychological Science, 6, 3-5.

Büssing, A. (2012). Measures. In: M. Cobb, C. M. Puchalski, \& B. Rumbold (Eds.), Oxford textbook of spirituality in healthcare (pp. 323-331). New York, NY: Oxford University Press.

Clark, A. (1999). An embodied cognitive science? Trends in Cognitive Sciences, 3, 345-351.

Conway, P., \& Gawronski, B. (2013). Deontological and utilitarian inclinations in moral decision making: A process dissociation approach. Journal of Personality and Social Psychology, 104, 216-235.

Crawford, L. E. (2009). Conceptual metaphors of affect. Emotion Review, 1, 129-139.

DesCamp, M. T., \& Sweetser, E. E. (2005). Metaphors for God: Why and how do our choices matter for humans? The application of contemporary cognitive linguistics research to the debate on God and metaphor. Pastoral Psychology, 53, 207-238. 
Epstein, S. (2003). Cognitive-experiential self-theory of personality. In: T. Millon \& M. J. Lerner (Eds.), Handbook of psychology: Personality and social psychology (pp. 159-184). Hoboken, NJ: John Wiley \& Sons.

Evans, J. St. B. T. (2008). Dual-processing accounts of reasoning, judgment, and social cognition. Annual Review of Psychology, 59, 255-278.

Fetterman, A. K. (2016). On god-belief and feeling clean: Daily experiences are related to feeling clean, particularly for those high in god-belief. Social Psychology and Personality Science, 7, 552-559.

Fetterman, A. K., \& Robinson, M. D. (2013). Do you use your head or follow your heart? Selflocation predicts personality, emotion, decision making, and performance. Journal of Personality and Social Psychology, 105, 316-334.

Francis, L. J., \& Wilcox, C. (1996). Religion and gender orientation. Personality and Individual Differences, 20, 119-121.

Frederick, S. (2005). Cognitive reflection and decision making. The Journal of Economic Perspectives, 19, 25-42.

Gervais, W. M., \& Norenzayan, A. (2012). Analytic thinking promotes religious disbelief. Science, 336, 493-496.

Gibbs, R. (2011). Evaluating conceptual metaphor theory. Discourse Processes, 48, 529-562.

Gilead, M., Gal, O., Polak, M., \& Cholow, Y. (2014). The role of nature and nurture in conceptual metaphors: The case of gustatory priming. Social Psychology, 46, 167-173.

Gleichgerrcht, E., \& Young, L. (2013). Low levels of empathetic concern predict utilitarian moral judgment. PLoS ONE, 8, e60418. 
Goldberg, L. R. (1999). A broad-bandwidth, public domain, personality inventory measuring the lower level facets of several five-factor models. In: I. Mervielde, I. Deary, F. De Fruyt, \& F. Ostendorf (Eds.), Personality psychology in Europe (Vol. 7, pp. 7-28). Tilburg, The Netherlands: Tilburg University Press.

Greene, J. D. (2011). Emotion and morality: A tasting menu. Emotion Review, 3, 227-229.

Haidt, J. (2013). Moral psychology for the twenty-first century. Journal of Moral Education, 42, 281-297.

Hayes, A. F. (2013). Introduction to mediation, moderation, and conditional process analysis: A regression-based approach. New York, NY: Guilford Press.

Heintzelman, S. J., \& King, L. A. (2016). Meaning in life and intuition. Journal of Personality and Social Psychology, 110, 477-492.

Jack, A. I., Dawson, A. J., Begany, K. L., Leckie, R. L., Barry, K. P., Ciccia, A. H., et al. (2013). fMRI reveals reciprocal inhibition between social and physical cognitive domains. NeuroImage, 66, 385-401.

Jack, A. I., Friedman, J. P., Boyatzis, R. E., \& Taylor, S. N. (2016). Why do you believe in God? Relationships between religious belief, analytic thinking, mentalizing and moral concern. PLoS ONE, 11, e0149989.

John, O. P., \& Srivastava, S. (1999). The Big Five trait taxonomy: History, measurement, and theoretical perspectives. In: L. A. Pervin \& O. P. John (Eds.), Handbook of personality: Theory and research ( $2^{\text {nd }}$ ed., pp. 102-138). New York, NY: Guilford Press.

Jost, J. T. (2006). The end of the end of ideology. American Psychologist, 61, 651-670.

Kövecses, Z. (2005). Metaphor in culture: Universality and variation. New York, NY: Cambridge University Press. 
Lakoff, G., \& Johnson, M. (1980). Metaphors we live by. Chicago, IL: University of Chicago Press.

Lakoff, G., \& Johnson, M. (1999). Philosophy in the flesh: The embodied mind and its challenge to Western thought. New York, NY: Basic Books.

Landau, M. J. (2018). Using metaphor to find meaning in life. Review of General Psychology, 22, 62-72.

Landau, M. J., Meier, B. P., \& Keefer, L. A. (2010). A metaphor-enriched social cognition. Psychological Bulletin, 136, 1045-1067.

Lee, S. W. S. (2016). Multimodal priming of abstract constructs. Current Opinion in Psychology, $12,37-44$

Lieberman, M. D., \& Eisenberger, N. I. (2005). Conflict and habit: A social cognitive neuroscience approach to the self. In: A. Tesser, J. V. Wood, \& D. A. Stapel (Eds.), On building, defending and regulating the self: A psychological perspective (pp. 77-102). New York, NY: Psychology Press.

Limanowski, J., \& Hecht, H. (2011). Where do we stand on locating the self? Psychology, 2, 312-317.

Lindeman, M., \& Aarnio, K. (2007). Superstitious, magical, and paranormal beliefs: An integrative model. Journal of Research in Personality, 41, 731-744.

Lowicki, P., \& Zajenkowski, M. (2017). No empathy for people nor for God: The relationship between the Dark Triad, religiosity and empathy. Personality and Individual Differences, 115, 169-173.

MacKinnon, D. P., \& Fairchild, A. J. (2009). Current directions in mediation analysis. Current Directions in Psychological Science, 18, 16-20. 
Markstrom, C. A., Huey, E., Stile, B. M., \& Krause, A. L. (2010). Frameworks of caring and helping in adolescence: Are empathy, religiosity, and spirituality related constructs? Youth \& Society, 42, 59-80.

Meier, B. P., Robinson, M. D., \& Clore, G. L. (2004). Why good guys wear white: Automatic inferences about stimulus valence based on brightness. Psychological Science, 15, 82-87.

Morgan, J. (2016). Religion and dual-process cognition: A continuum of styles or distinct types? Religion, Brain \& Behavior, 6, 112-129.

Norenzayan, A., \& Hansen, I. G. (2006). Belief in supernatural agents in the face of death. Personality and Social Psychology Bulletin, 32, 174-187.

Paxton, J. M., Ungar, L., \& Greene, J. D. (2012). Reflection and reasoning in moral judgment. Cognitive Science, 36, 163-177.

Pennycook, G., Cheyne, J. A., Barr, N., Koehler, D. J., \& Fugelsang, J. A. (2014). Cognitive style and religiosity: The role of conflict detection. Memory \& Cognition, 42, 1-10.

Pennycook, G., Ross, R. M., Koehler, D. J., \& Fugelsang, J. A. (2016). Atheists and agnostics are more reflective than religious believers: Four empirical studies and a meta-analysis. PLoS ONE, 11, e0153039.

Petty, R. E., Fabrigar, L. R., \& Wegener, D. T. (2003). Emotional factors in attitudes and persuasion. In: R. J. Davidson, K. R. Scherer, \& H. H. Goldsmith (Eds.), Handbook of affective sciences (pp. 752-772). New York, NY: Oxford University Press.

Plato (1987 trans.). The republic ( $2^{\text {nd }}$ ed., D. Lee, Trans.). New York, NY: Penguin Books. Rios, K., Cheng, Z. H., Totton, R. R., \& Shariff, A. F. (2015). Negative stereotypes cause Christians to underperform in and disidentify with science. Social Psychological and Personality Science, 6, 959-967. 
Robinson, M. D. (2007). Personality, affective processing, and self-regulation: Toward processbased views of extraversion, neuroticism, and agreeableness. Social and Personality Psychology Compass, 1, 223-235.

Robinson, M. D., \& Fetterman, A. K. (2014). Toward a metaphor-enriched personality psychology. In: M. Landau, M. D. Robinson, \& B. P. Meier (Eds.), The power of metaphor: Examining its influence on social life (pp. 133-152). Washington, DC: American Psychological Association.

Saraglou, V. (2002). Religion and the five factors of personality: A meta-analytic review. Personality and Individual Differences, 32, 15-25.

Shenhav, A., Rand, D. G., \& Greene, J. D. (2012). Divine intuition: Cognitive style influences belief in God. Journal of Experimental Psychology: General, 141, 423-428.

Swan, T. (2009). Metaphors of body and mind in the history of English. English Studies, 90, 460-475.

Szekely, R. D., Opre, A., \& Miu, A. C. (2015). Religiosity enhances emotion and deontological choice in moral dilemmas. Personality and Individual Differences, 79, 104-109.

Van Leeuwen, N. (2014). Religious credence is not factual belief. Cognition, 133, 698-715. Wink, P., Ciciolla, L., Dillon, M., \& Tracy, A. (2007). Religiousness, spiritual seeking, and personality: Findings from a longitudinal study. Journal of Personality, 75, 1051-1070.

Yu, N. (2003). Chinese metaphors of thinking. Cognitive Linguistics, 14, 141-165.

Zuckerman, P. (2007). Atheism: Contemporary numbers and patterns. In: M. Martin (Ed.), The Cambridge companion to atheism (pp. 47-65). New York, NY: Cambridge University Press. 


\section{Footnotes}

${ }^{1}$ Study 4 consists of a combination of all the studies conducted during the first author's tenure in this lab that included the self-location and religiosity questions. As such, this study can be considered a complete picture of the data collected on these variables during this time period.

${ }^{2}$ A subset $(n=111)$ of the sample also completed Goldberg (1999) measures of conscientiousness (e.g., "get chores done right away”) and openness (e.g., "have a rich vocabulary”). Self-location $(-1=$ head; $+1=$ heart $)$ did not vary by conscientiousness, $r=-.11, p$ $=.235$, or openness, $r=.09, p=.346$, and neither conscientiousness, $r=.00, p=.970$, nor openness, $r=-.16, p=.090$, significantly predicted beliefs in God. 
Table 1

Multiple Regression Results from Study 1

\begin{tabular}{lllll}
\hline Outcome & Predictor & $t$ & $p$ & Beta \\
\hline Religiosity & Self-location & 5.23 & $<.001$ & .21 \\
& Participant sex & 1.48 & .139 & .06 \\
Centrality & Self-location & 5.83 & $<.001$ & .24 \\
Importance & Participant sex & 0.49 & .622 & .02 \\
& Self-location & 5.54 & $<.001$ & .23 \\
Spirituality & Participant sex & 0.85 & .396 & .04 \\
& Self-location & 3.96 & $<.001$ & .16 \\
& Participant sex & 1.16 & .246 & .05 \\
\hline
\end{tabular}

Note: The self-location and participant sex predictors were scored such that heart-locators $(-1=$ head; +1 = heart $)$ and women $(-1=$ male; $+1=$ female $)$ received higher scores. Centrality = centrality of religious beliefs; Importance = importance of religious beliefs (see text) 